\title{
BMJ
}

\section{Population based screening for chronic kidney disease: cost effectiveness study}

\author{
Braden Manns, associate professor of medicine, ${ }^{1,2,3,4}$ Brenda Hemmelgarn, associate professor of medicine, 1,23,4 \\ Marcello Tonelli, associate professor of medicine, ${ }^{4,5}$ Flora Au, research analyst, ${ }^{2,4}$ T Carter Chiasson, BHSc student, ${ }^{4}$ \\ James Dong, research analyst, ${ }^{4,5}$ Scott Klarenbach, associate professor of medicine ${ }^{4,5}$ on behalf of the Alberta Kidney \\ Disease Network
}

\section{${ }^{1}$ Department of Medicine, University of Calgary, Calgary, Alberta, Canada \\ ${ }^{2}$ Community Health Sciences, University of Calgary, Calgary \\ ${ }^{3}$ Libin Cardiovascular Institute of Alberta, University of Calgary, Calgary \\ ${ }^{4}$ Alberta Kidney Disease Network, Calgary \\ ${ }^{5}$ Department of Medicine, Division of Nephrology, University of Alberta, Edmonton, Alberta \\ Correspondence to: B Manns, Foothills Medical Centre, 140329th St. NW Calgary, Alberta Canada T2N 2T9 \\ Braden.}

Manns@albertahealthservices.ca

Cite this as: $B M J$ 2010;341:c5869 doi:10.1136/bmi.c5869

\section{ABSTRACT}

Objective To determine the cost effectiveness of one-off population based screening for chronic kidney disease based on estimated glomerular filtration rate.

Design Cost utility analysis of screening with estimated glomerular filtration rate alone compared with no screening (with allowance for incidental finding of cases of chronic kidney disease). Analyses were stratified by age, diabetes, and the presence or absence of proteinuria. Scenario and sensitivity analyses, including probabilistic sensitivity analysis, were performed. Costs were estimated in all adults and in subgroups defined by age, diabetes, and hypertension.

Setting Publicly funded Canadian healthcare system. Participants Large population based laboratory cohort used to estimate mortality rates and incidence of end stage renal disease for patients with chronic kidney disease over a five year follow-up period. Patients had not previously undergone assessment of glomerular filtration rate.

Main outcome measures Lifetime costs, end stage renal disease, quality adjusted life years (QALYs) gained, and incremental cost per QALY gained.

Results Compared with no screening, population based screening for chronic kidney disease was associated with an incremental cost of \$C463 (Canadian dollars in 2009; equivalent to about $£ 275$, $€ 308$, US $\$ 382$ ) and a gain of 0.0044 QALYs per patient overall, representing a cost per QALY gained of \$C104 900. In a cohort of 100000 people, screening for chronic kidney disease would be expected to reduce the number of people who develop end stage renal disease over their lifetime from 675 to 657 . In subgroups of people with and without diabetes, the cost per QALY gained was \$C22 600 and \$C572 000, respectively. In a cohort of 100000 people with diabetes, screening would be expected to reduce the number of people who develop end stage renal disease over their lifetime from 1796 to 1741 . In people without diabetes with and without hypertension, the cost per QALY gained was \$C334 000 and \$C1 411100 , respectively. Conclusions Population based screening for chronic kidney disease with assessment of estimated glomerular filtration rate is not cost effective overall or in subgroups of people with hypertension or older people. Targeted screening of people with diabetes is associated with a cost per QALY that is similar to that accepted in other interventions funded by public healthcare systems.

\section{INTRODUCTION}

End stage renal disease and its precursor chronic kidney disease are emerging public health problems because of their associated adverse clinical outcomes, poor quality of life, and high healthcare costs. Given that chronic kidney disease (defined as glomerular filtration rate below $\left.60 \mathrm{ml} / \mathrm{min} / 1.73 \mathrm{~m}^{2}\right)$ is often not detected until it is advanced, screening programmes using blood or urine tests have been recommended. ${ }^{1-3}$ With population based screening, however, there are potential benefits (such as early identification and treatment of affected patients) and drawbacks (such as identification of patients with only mild disease, in whom additional treatment might not be warranted). ${ }^{4}$

Several studies have examined the effectiveness of screening for chronic kidney disease with estimated glomerular filtration rate or urinalysis. ${ }^{5-9}$ Previous studies of screening in high risk groups have found that it would identify one person with disease for every three to six people screened, ${ }^{5-10}$ whereas population based screening would detect one for every 16-21 people screened. ${ }^{1011}$ Existing cost effectiveness studies have examined screening only with urinalysis. ${ }^{12}{ }^{13}$ As only $26 \%$ and $3 \%$ of North Americans with glomerular filtration rate $<30 \mathrm{ml} / \mathrm{min} / 1.73 \mathrm{~m}^{2}$, and $30-60 \mathrm{ml} / \mathrm{min} /$ $1.73 \mathrm{~m}^{2}$, respectively, have macroalbuminuria on urinalysis, this form of screening would be expected to miss a considerable proportion of people with chronic kidney disease. ${ }^{10}$

While clinical practice guidelines for chronic kidney disease from the National Kidney Foundation/Kidney Dialysis Outcomes Quality Initiative have recommended targeted screening of high risk patients, including those with diabetes or hypertension and aged $>60,{ }^{114}$ others have suggested a population based approach. ${ }^{41516}$ The International Federation of Kidney Foundations recently surveyed its 28 member nations on the existence of screening programmes for chronic kidney disease, and 24 reported some form of screening activity. ${ }^{17}$ While most programmes entailed 
Table 1|Baseline characteristics of patient cohort from Alberta Kidney Disease Network. Figures are numbers (percentages) of patients unless otherwise specified

\begin{tabular}{|c|c|c|c|}
\hline & $\begin{array}{c}\text { Overall } \\
(n=290613)\end{array}$ & $\begin{array}{l}\text { People with diabetes } \\
\quad(n=30277)\end{array}$ & $\begin{array}{c}\text { People without } \\
\text { diabetes }(n=260336)\end{array}$ \\
\hline Mean (SD) age (years) & $55(18)$ & 64 (14) & $54(18)$ \\
\hline Aged $\geq 65$ & $90090(31)$ & $15139(50)$ & 75497 (29) \\
\hline Women & $168555(58)$ & $14533(48)$ & $153598(59)$ \\
\hline \multicolumn{4}{|l|}{ CKD (estimated GFR in $\mathrm{ml} / \mathrm{min} / 1.73 \mathrm{~m}^{2}$ ): } \\
\hline None $(\geq 60)$ & $235160(81)$ & $19788(65)$ & $215372(83)$ \\
\hline Stage $3(30-59.9)$ & $51591(18)$ & $9162(30)$ & $42429(16)$ \\
\hline Stage 4 (15-29.9) & 2962 (1) & $1000(3)$ & 1962 (1) \\
\hline Stage 5 («15) & $900(0)$ & 327 (1) & $573(0)$ \\
\hline Determination of proteinuria* & $12754 / 55453(23)$ & $9021 / 10489(86)$ & 7644/44964 (17) \\
\hline Presence of proteinuria* ${ }^{\star}$ & $893 / 12754(7)$ & $812 / 9021$ (9) & 459/7644 (6) \\
\hline \multicolumn{4}{|l|}{ Comorbidity (\%)*: } \\
\hline Myocardial infarction & $4658 / 55453(8)$ & $1704 / 10489(16)$ & $2954 / 44964$ (7) \\
\hline Peripheral vascular disease & $2462 / 55453(4)$ & $909 / 10489(9)$ & 1553/44 964 (3) \\
\hline Cerebrovascular disease & $3295 / 55453(6)$ & $1035 / 10489(10)$ & 2260/44 $964(5)$ \\
\hline Median (IQR) Charlson comorbidity score* & $0(0-1)$ & $1(0-3)$ & $0(0-0)$ \\
\hline
\end{tabular}

$\mathrm{CKD}=$ chronic kidney disease; $\mathrm{GFR}=$ glomerular filtration rate; $I Q R=$ interquartile range.

*Patients with CKD stage 3-5 only

†Among people with CKD (GFR $<60 \mathrm{ml} / \mathrm{min} / 1.73 \mathrm{~m}^{2}$ ), proteinuria defined as present if urine dipstick was > trace or urine protein:creatinine ratio $>23 \mathrm{mg} / \mathrm{mmol}(>200 \mathrm{mg} / \mathrm{g}) .^{19}$

screening for disease among high risk groups, including those with hypertension, diabetes, and a family history of chronic kidney disease and older people, a few countries, including Hong Kong, Japan, and the Netherlands, have active population based screening programmes. Given the current interest in screening, as well as the controversy concerning its optimal use, we assessed the cost effectiveness of population based screening for chronic kidney disease based on estimated glomerular filtration rate alone (compared with no screening) in all adults and in subgroups of people defined by age, diabetes, and hypertension.

\section{METHODS}

\section{Overview and validation}

We carried out an incremental cost utility analysis of one-off screening for chronic kidney disease with estimated glomerular filtration rate compared with no

\section{Overview of analysis}

- The prevalence of undiagnosed chronic kidney disease in different subgroups of patients stratified by age ( $(65$ or $\geq 65$ ) and diabetes was determined from a North American population based survey ${ }^{10}$

- The natural course of chronic kidney disease was then determined within the Alberta Kidney Disease Network, ${ }^{18}$ a large population based laboratory cohort of patients, with mortality rates and incidence of end stage renal disease estimated over a five year follow-up period

- Screening for chronic kidney disease would be expected to identify patients with no previous diagnosis who could then receive angiotensin blockade

- The relative risks of end stage renal disease and death associated with angiotensin blockade were taken from high quality published meta-analyses

- This information was combined with decision analysis to examine the long term outcomes and costs for a strategy of screening for chronic kidney disease and subsequent management of patients compared with no screening (disease undiagnosed and untreated until detected incidentally during routine care) screening in adults with no previous assessment of glomerular filtration rate. The box shows a high level overview of the modelling process.

In the base case analysis we used the perspective of the publicly funded healthcare system. Health benefits were measured in cases of end stage renal disease prevented and quality adjusted life years (QALYs) gained over a lifetime. We also assessed the incremental cost associated with screening for chronic kidney disease and measured the incremental cost per QALY gained. Costs and benefits were discounted at 5\% annually. All costs were inflated to 2009 Canadian dollars $(1 \$ \mathrm{C}=$ $£ 0.59=€ 0.67=$ US $\$ 0.83$ ) by using the Canadian healthcare consumer price index.

\section{Computer simulation model}

We constructed a Markov model using decision analysis software (TreeAge Pro Suite 2007, Williamstown, MA) in accordance with existing guidelines for economic evaluation. ${ }^{19}$ Base case analyses were performed with Markov cohort simulation with transitions modelled on an annual basis, though we used first order Monte Carlo simulation to determine the incidence of end stage renal disease over time. We considered several health states in both the screening and no screening strategies, including people without chronic kidney disease, those with non-dialysis chronic kidney disease, patients receiving dialysis, and patients with a functioning transplant.

Model validity was established, ${ }^{20}$ including internal validation with primary clinical data $\left(\mathrm{R}^{2}\right.$ between model outcomes and primary data was $>0.97$ for both end stage renal disease and mortality at five years) and external validity by comparing with other published reports. ${ }^{2122}$ Among patients with chronic kidney disease, mortality and end stage renal disease was $24 \%$ and $2.7 \%$ at five years and $71 \%$ and $4.1 \%$ at 20 years, respectively. Several models were evaluated, and, given the excellent performance of all models, we used the simplest and most transparent model, where chronic kidney disease is represented as one health state (as opposed to modelling patients with varying severity of chronic kidney disease as three separate disease states $\left.^{1}\right)$, in accordance with optimal modelling guidelines. ${ }^{20}$ Additional benefits of modelling with only one health state is that it offers increased flexibility to incorporate estimates of benefit (that is, relative risk for end stage renal disease and death) as reported in clinical trials, compared with models that use several distinct stages of chronic kidney disease based on severity of disease.

\section{Data inputs}

We based the prevalence of non-dialysis chronic kid ney disease (estimated glomerular filtration rate $\left.<60 \mathrm{ml} / \mathrm{min} / 1.73 \mathrm{~m}^{2}\right)$ on the results of the National Health and Nutrition Examination Survey III, a representative survey of the North American population stratified by age and the presence of diabetes. ${ }^{10}$ In the survey, conducted by the National Center for Health Statistics in the United States, data (including estimated 
Table 2 |Annual probability of end stage renal disease and mortality in people with chronic kidney disease in Alberta Kidney Disease Patient cohort, stratified by diabetes and presence of proteinuria*

\begin{tabular}{|c|c|c|c|c|}
\hline \multirow[b]{2}{*}{ Variables } & \multicolumn{2}{|c|}{ Without diabetes $(n=44964)$} & \multicolumn{2}{|c|}{ With diabetes $(n=10489)$} \\
\hline & No proteinuria & Proteinuria & No proteinuria & Proteinuria \\
\hline \multicolumn{5}{|c|}{ End stage renal disease } \\
\hline \multicolumn{5}{|l|}{ Age «65: } \\
\hline Year 1 & 0.0037 & 0.0523 & 0.0049 & 0.0547 \\
\hline Year 2 & 0.0024 & 0.0380 & 0.0013 & 0.0608 \\
\hline Year 3 & 0.0011 & 0.0336 & 0.0045 & 0.0630 \\
\hline Year 4 & 0.0031 & 0.0296 & 0.0053 & 0.0703 \\
\hline Year 5 & 0.0014 & 0.0340 & 0.0083 & 0.0597 \\
\hline \multicolumn{5}{|l|}{ Age $\geq 65$ : } \\
\hline Year 1 & 0.0011 & 0.0274 & 0.0029 & 0.0377 \\
\hline Year 2 & 0.0015 & 0.0243 & 0.0015 & 0.0340 \\
\hline Year 3 & 0.0008 & 0.0158 & 0.0027 & 0.0193 \\
\hline Year 4 & 0.0022 & 0.0235 & 0.0023 & 0.0232 \\
\hline Year 5 & 0.0015 & 0.0255 & 0.0018 & 0.0306 \\
\hline \multicolumn{5}{|l|}{ Mortality } \\
\hline \multicolumn{5}{|l|}{ Age <65: } \\
\hline Year 1 & 0.0024 & 0.0182 & 0.0122 & 0.0369 \\
\hline Year 2 & 0.0054 & 0.0299 & 0.0186 & 0.0478 \\
\hline Year 3 & 0.0116 & 0.0222 & 0.0240 & 0.0243 \\
\hline Year 4 & 0.0115 & 0.0288 & 0.0234 & 0.0690 \\
\hline Year 5 & 0.0136 & 0.0194 & 0.0361 & 0.0409 \\
\hline Year 6-10† & 0.008 & 0.028 & 0.0258 & 0.0559 \\
\hline Year 11-15† & 0.012 & 0.045 & 0.0252 & 0.0523 \\
\hline Year 16-20† & 0.015 & 0.044 & 0.0321 & 0.0550 \\
\hline Year 21-25† & 0.019 & 0.053 & 0.0405 & 0.0632 \\
\hline Year 26-30† & 0.027 & 0.069 & 0.0465 & 0.0954 \\
\hline Year 31-35† & 0.032 & 0.053 & 0.0591 & 0.0912 \\
\hline Year 36-40† & 0.053 & 0.093 & 0.0742 & 0.1249 \\
\hline Year 41-45† & 0.066 & 0.131 & 0.0993 & 0.0999 \\
\hline Year 45-50† & 0.052 & 0.135 & 0.1459 & 0.1973 \\
\hline \multicolumn{5}{|l|}{ Age $\geq 65$ : } \\
\hline Year 1 & 0.0124 & 0.0570 & 0.0258 & 0.0640 \\
\hline Year 2 & 0.0208 & 0.0759 & 0.0483 & 0.0883 \\
\hline Year 3 & 0.0288 & 0.0842 & 0.0528 & 0.0889 \\
\hline Year 4 & 0.0363 & 0.0907 & 0.0613 & 0.1019 \\
\hline Year 5 & 0.0438 & 0.0962 & 0.0638 & 0.0937 \\
\hline Year 6-10† & 0.030 & 0.079 & 0.0545 & 0.0841 \\
\hline Year 11-15† & 0.042 & 0.110 & 0.0646 & 0.1237 \\
\hline Year 16-20† & 0.061 & 0.165 & 0.0940 & 0.1165 \\
\hline Year 21-25† & 0.079 & 0.129 & 0.1095 & 0.1559 \\
\hline
\end{tabular}

*Incidence of proteinuria at age $<65$ was 0.20 in those without diabetes and 0.32 in those with diabetes and 0.16 and 0.22 , respectively, at age $\geq 65$. $^{10}$

†Based on probability of mortality observed in progressively older patients. For example, mean age of patients $<65$ was 55 , and mortality over first five years for this cohort is reported per year by using full cohort. Mortality for years 6-10 estimated on mortality observed for patients with mean age 60 (range 57-63) within each of four diabetes/proteinuria subgroups, while mortality for years 11-15 was based on mortality observed for patients with mean age 65 (63-68) within each of four diabetes/proteinuria subgroups.

glomerular filtration rate) were collected with rigorous methods according to standardised protocols. ${ }^{23}$

We also used data from the Alberta Kidney Disease Network, ${ }^{18}$ a repository of laboratory data for routinely collected tests (including estimated glomerular filtration rate) for the entire province of Alberta, Canada. Patients in the laboratory repository are linked to provincial healthcare programmes, which care for all

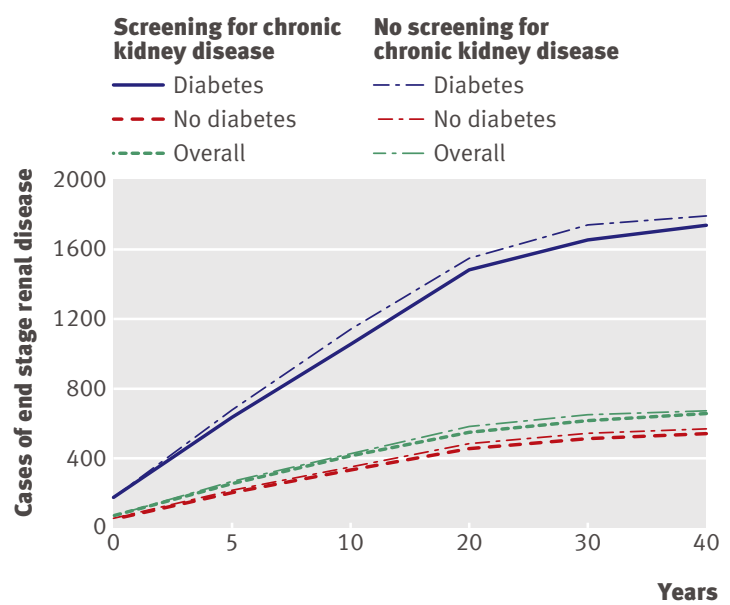

Fig 1| Impact of screening for chronic kidney disease in cohort of 100000 people on number of cases of end stage renal disease overall and for people with and without diabetes

dialysis and transplant patients, ${ }^{24}$ and to provincial administrative data (using the unique provincial health number) to obtain demographic information (including death) and details regarding use of healthcare resources (physician claims, admission to hospital, and use of prescription drugs (for people aged $\geq 65)$ ). ${ }^{18}$

Data from the network enabled us to estimate the annual incidence of end stage renal disease and death in a cohort of Albertans receiving routine care between May 2002 and December 2007 (table 1). The initial and subsequent glomerular filtration rate for these patients was estimated with an equation from the Four Variable Modification of Diet in Renal Disease Study, ${ }^{25}$ with the baseline rate being defined by the mean estimated rate of all measurements during the first year. Diabetes mellitus was identified from hospital discharge records and physicians' claims, ${ }^{26}$ and other chronic medical conditions were identified with validated algorithms. ${ }^{2728}$ Proteinuria was defined as more than trace on a urine dipstick or if the urine protein:creatinine ratio was $>23 \mathrm{mg} / \mathrm{mmol}(>200 \mathrm{mg} / \mathrm{g}) .{ }^{18}$

The cohort included 290613 individuals, of whom 55453 had chronic kidney disease and 30277 had diabetes. All participants were followed to ascertain the incidence of death, end stage renal disease, and renal replacement therapy until 31 December 2007. Annual rates of these outcomes (stratified by age, presence of diabetes and presence of proteinuria) were estimated for up to five years after the index measurement of glomerular filtration rate, with censoring at end stage renal disease, death, or 31 December 2007 (table 2 and table 3).

\section{Mortality}

For people without chronic kidney disease, age dependent population mortality rates were estimated from observed rates for Canadians. ${ }^{29}$ For people with chronic kidney disease, mortality rates were based on the annual rate observed within the Alberta Kidney 
Disease Network cohort after the initial assessment of estimated glomerular filtration rate. We accounted for age related increases in mortality in those with chronic kidney disease based on the observed mortality rates for patients in different age groups in the network (table 2 and table 3 ).

\section{Adherence with screening and incidental case finding} We assumed that $50 \%$ of people would agree to screening, which requires venipuncture ${ }^{30}$ As estimation of glomerular filtration rate can also occur during routine care, irrespective of screening, we assumed that a proportion of unscreened people would undergo such assessment each year. Using data from the network (to determine the number of people undergoing their first creatinine measurements each year) and the 2006 Canadian census (to define the total Alberta population $^{31}$ ), we estimated the annual likelihood of undergoing incidental screening for chronic kidney disease in this previously unscreened population.

\section{Diagnostic investigation for people in whom screening identified chronic kidney disease}

We assumed that all people with newly diagnosed chronic kidney disease would undergo evaluation by a nephrologist, including a standard laboratory investigation (table 4). This assumption was tested in a sensitivity analysis, in which we assumed that only $20 \%$ of patients were assessed by a nephrologist with the remainder managed by a primary care physician. Consistent with previous surveys of physicians, ${ }^{1232}$ we also assumed that a kidney biopsy would be done in $5 \%$ and $20 \%$ of people with incident chronic kidney disease with and without diabetes.

\section{Effectiveness of angiotensin blockade for people with chronic kidney disease}

The benefit of screening for chronic kidney disease is assumed to be the detection of previously undiagnosed

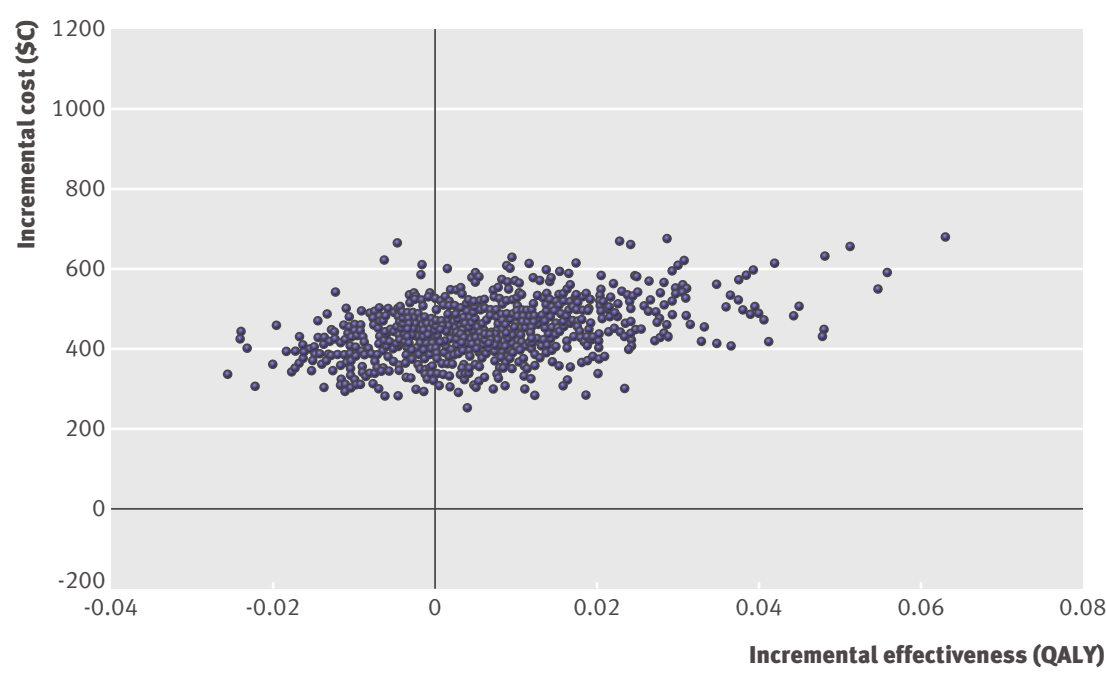

Fig 2 | Incremental cost effectiveness of population based screening for chronic kidney disease compared with no screening overall
Table $3 \mid$ Annual probabilities of events in people with end stage renal disease

\begin{tabular}{|c|c|}
\hline Variables & Probability \\
\hline \multicolumn{2}{|c|}{ Annual mortality on dialysis $(95 \% \mathrm{Cl})$} \\
\hline Age $<65$ & $0.077(0.072 \text { to } 0.083)^{43}$ \\
\hline Age $\geq 65$ & $0.212(0.202 \text { to } 0.223)^{43}$ \\
\hline \multicolumn{2}{|c|}{ Annual mortality for patients with functioning transplant* } \\
\hline \multicolumn{2}{|l|}{ Age <65: } \\
\hline Year 1 & 0.012 \\
\hline Year 2 & 0.007 \\
\hline Year 3 & 0.001 \\
\hline Year 4 & 0.007 \\
\hline Year 5 & 0.003 \\
\hline \multicolumn{2}{|l|}{ Age $\geq 65$ : } \\
\hline Year 1 & 0.071 \\
\hline Year 2 & 0.051 \\
\hline Year 3 & 0.054 \\
\hline Year 4 & 0.043 \\
\hline Year 5 & 0.030 \\
\hline
\end{tabular}

Initial probability of treatment being dialysis (rather than transplant) after developing end stage renal disease*

\begin{tabular}{lc}
\hline Age $<65$ & 0.854 \\
\hline Age $\geq 65$ & 0.989 \\
\hline Subsequent annual probability of transplant for dialysis patients* \\
\hline Age $<65$ & 0.108 \\
\hline Age $\geq 65$ & 0.008
\end{tabular}

Annual probability of transplant failure requiring return to dialysis $(95 \%$ CI)

All $\quad 0.04(0 \text { to } 0.1)^{62}$

*From Alberta Kidney Disease Network cohort.

disease, enabling appropriate assessment and management. While detection of previously undiagnosed disease or undiagnosed severe glomerulonephritis requiring immunosuppression is possible, nearly all people detected by screening would have stage 3 chronic kidney disease unrelated to glomerulonephritis ${ }^{10}$; as such, management would focus on control of blood pressure through the use of angiotensin blockade, particularly in people with proteinuria. ${ }^{33-35}$ While it is possible that people with chronic kidney disease identified by screening would already be receiving angiotensin blockade, given that the target population consisted of people in whom glomerular filtration rate had not previously been measured, we assumed that this would not be the case.

We assumed that people found to have chronic kidney disease would receive an ACE (angiotensin converting enzyme) inhibitor or angiotensin blocker (if tolerated), with a target blood pressure of $<130$ / $80 \mathrm{~mm} \mathrm{Hg}$. We based the effectiveness of angiotensin blockade by conducting a focused literature search that identified relevant high quality meta-analyses and randomised trials in people with chronic kidney disease. ${ }^{335-42}$ As the effectiveness of angiotensin blockade at reducing end stage renal disease and death varies by diabetes and proteinuria status, we estimated the relative risk for these outcomes separately in these four subgroups (table 4). 
Table $4 \mid$ Additional clinical information required for base case analysis. Data shown with $95 \%$ confidence intervals when available

\begin{tabular}{|c|c|c|c|}
\hline Variables & $\begin{array}{l}\text { Mean base case estimate } \\
\text { overall }(95 \% \mathrm{Cl})\end{array}$ & \multicolumn{2}{|c|}{ Base case estimate in people with CKD } \\
\hline Proportion of general population aged $<65$ & $0.629^{31}$ & - & - \\
\hline Age $<65$ & $0.044^{61}$ & - & - \\
\hline Age $\geq 65$ & $0.183^{61}$ & - & - \\
\hline Age $<65$ & & $0.035^{10}$ & $0.075^{10}$ \\
\hline Age $\geq 65$ & & $0.186^{10}$ & $0.277^{10}$ \\
\hline $\begin{array}{l}\text { Proportion of patients identified as having CKD in } \\
\text { whom kidney biopsy is undertaken }\end{array}$ & - & $0.20^{32}$ & 0.051 \\
\hline Adherent with screening & $0.50(0.25 \text { to } 0.75)^{30}$ & & - \\
\hline Age $\geq 65$ on dialysis & $0.572(0.55$ to 0.8$)$ & - & - \\
\hline Patients with functioning transplant & $0.816(0.65 \text { to } 0.9)^{4564}$ & - & - \\
\hline \multicolumn{4}{|c|}{ Relative risks associated with angiotensin blockade in patients with CKD: } \\
\hline ESRD in people with proteinuria & - & $0.59(0.37 \text { to } 0.94)^{\star 39}$ & $0.64(0.4 \text { to } 1.03)^{35}$ \\
\hline ESRD in people without proteinuria & - & $1.01(0.44 \text { to } 2.32)^{39}$ & $1.00(0.67 \text { to } 2.30)^{353765}$ \\
\hline Death in people with proteinuria & - & $1.00(0.55 \text { to } 2.93)^{\star 38}$ & $0.79(0.63 \text { to } 0.99)^{35}$ \\
\hline Death in people without proteinuria & - & $1.00(0.36 \text { to } 2.17)^{38}$ & $0.84(0.75$ to 0.95$) t^{3765}$ \\
\hline \multicolumn{4}{|l|}{ Annual discount rate: } \\
\hline
\end{tabular}

$\mathrm{CKD}=$ chronic kidney disease; $\mathrm{ESRD}=$ end stage renal disease.

*While Jafar et al ${ }^{39}$ and Giatras et al ${ }^{38}$ both present data from Angiotensin Converting Enzyme Inhibition and Progressive Renal Disease Study Group, who analysed patient level data from 10 and 11 randomised trials, respectively, comparing ACE inhibitors in patients without diabetes with CKD, data from Jafar et al is used for ESRD as it reports data stratified by proteinuria, while data from Giatras et al is used for mortality as they conducted analyses with and without including study of Maschio et al, ${ }^{66}$ a small randomised controlled trial reporting relative risk of mortality of 7.55 $(95 \% \mathrm{Cl} 0.95$ to 60.0$)$ associated with use of ACE inhibitor, which was thought implausible. Data from Giatras et al excluding this trial showed no significant different in relative risk of mortality associated with use of ACE inhibitors.

†While Strippoli et $\mathrm{al}^{35}$ presented relative risk of ESRD in patients with diabetes and CKD, most patients had nephropathy and baseline proteinuria. As such, relative risk of ESRD and mortality for patients with diabetes and proteinuria was estimated from Strippoli et al, ${ }^{35}$ while relative risk of ESRD and mortality for patients with diabetes without proteinuria was estimated from microHOPE study, ${ }^{37}$ which excluded patients with overt nephropathy.

\section{Costs related to screening}

For people without chronic kidney disease, screening included a visit to a primary care physician and measurement of glomerular filtration rate, at a cost of about $\$ \mathrm{C} 48$ (table 5). In patients found to have chronic kidney disease, the cost of screening was about \$C83, accounting for an additional follow-up visit to a physician.

Costs related to managing chronic kidney disease with and without dialysis

The cost of managing people with chronic kidney disease was assumed to be the incremental costs resulting from a new diagnosis, including those of nephrologist care, the requirement for angiotensin blockade, and laboratory monitoring (table 5). As admission to hospital in patients with stage 3-5 non-dialysis chronic kidney disease is usually because of comorbidity and because randomised trials of management of chronic kidney disease have not shown that interventions prevent admissions, we did not include the cost of admissions in our analysis. The annual cost of dialysis was estimated at \$C64218, assuming that nearly $81 \%$ of people were treated in haemodialysis centres. ${ }^{4344}$ The cost of transplantation was estimated at \$C84531 for year one and \$C35 545 for subsequent years. ${ }^{45}$

\section{Valuing health benefits}

Health benefits were measured in cases of end stage renal disease prevented and QALYs gained. We did not assume any difference in utility estimates for "diagnosed" and "undiagnosed" chronic kidney disease, as studies of antihypertensive therapy (the only additional treatment in people with diagnosed chronic kidney disease) suggest no significant impact on quality of life. ${ }^{46}$ We estimated utilities for relevant health states (dialysis and transplantation) based on contemporary Canadian studies. ${ }^{4547}$

\section{Sensitivity and scenario analyses}

Sensitivity and scenario analyses were performed to determine the impact of uncertainty on the results of the model by varying all key parameters through plausible ranges. We conducted an additional scenario analysis examining the cost effectiveness of screening in 
Table $5 \mid$ Average cost of care associated with managing patients with newly diagnosed chronic kidney disease (CKD) Figures are \$C, 2009

\begin{tabular}{|c|c|c|c|}
\hline \multirow[b]{2}{*}{ Costs with source } & \multicolumn{3}{|c|}{ Cost estimate by CKD stage* (GFR) } \\
\hline & $\begin{array}{c}\text { Stage } 3 \\
(30-60 \mathrm{ml} / \mathrm{min})\end{array}$ & $\begin{array}{c}\text { Stage } 4 \\
(15-30 \mathrm{ml} / \mathrm{min})\end{array}$ & $\begin{array}{c}\text { Stage 5 } \\
((15 \mathrm{ml} / \mathrm{min})\end{array}$ \\
\hline \multicolumn{4}{|l|}{ Cost of screening (Alberta Schedule of Medical Benefits): } \\
\hline People found to have CKD & & 83 & \\
\hline People without CKD & & 48 & \\
\hline \multicolumn{4}{|l|}{ Specialist visits for people found to have CKD (Alberta Schedule of Medical Benefits)†: } \\
\hline Year 1 & 226 & 226 & 302 \\
\hline Years 2 and on & 189 & 189 & 302 \\
\hline \multicolumn{4}{|l|}{ Testing for people with CKD: } \\
\hline \multicolumn{4}{|l|}{ Urine studies ${ }^{44} \mp:$} \\
\hline Year 1 & 130 & 130 & 130 \\
\hline Years 2 and on & 109 & 109 & 109 \\
\hline \multicolumn{4}{|l|}{ Haematology and serology ${ }^{44} \S:$} \\
\hline Year 1 & 129 & 180 & 326 \\
\hline Years 2 and on & 108 & 158 & 304 \\
\hline \multicolumn{4}{|l|}{ Radiological studies (year 1$)^{44}$ : } \\
\hline Renal ultrasonography ${ }^{44}$ & & 325 & \\
\hline \multicolumn{4}{|l|}{ Biopsy/pathology (year 1): } \\
\hline Renal biopsy (when indicated) ${ }^{44} \pi$ & & 538 & \\
\hline \multicolumn{4}{|l|}{ Medications for people with known CKD (all years): } \\
\hline ACE inhibitor ${ }^{6 * \star}$ & 378 & 378 & 378 \\
\hline Additional anti-hypertensives ${ }^{67}+\dagger$ & 857 & 857 & 857 \\
\hline $\begin{array}{l}\text { Mean cost of erythropoietin stimulating agent (ESA) for people with known CKD } \\
\text { receiving } E S A^{68} \mathrm{f \ddagger}\end{array}$ & & 2668/patient & \\
\hline Multidisciplinary CKD clinics $^{69}{ }^{70} \S \S$ & & 1590/patient & \\
\hline
\end{tabular}

$\mathrm{CKD}=$ chronic kidney disease; $\mathrm{GFR}=$ glomerular filtration rate.

*Total annual cost of managing patients with CKD (GFR $<60 \mathrm{ml} / \mathrm{min}$ ) based on proportion of patients with CKD stages 3, 4, and 5 (see table 1 ) and relative cost of managing patients with stages 3,4 , and 5 .

†Assumes that patients with stages 3 and 4 CKD are seen annually, while patients with non-dialysis stage 5 CKD are seen every four months.

$\ddagger$ Assumes that urine protein:creatinine ratio is monitored every 3 months, with urine protein electrophoresis conducted once in year 1 only.

$\S$ Assumes that complete blood count, electrolytes, serum phosphate, calcium, and albumin are measured every 3, 2, and 1 months for patients with

stages 3, 4, and 5 CKD, respectively, with serum protein electrophoresis being conducted once in year 1 only.

TOnly $20 \%$, and $5 \%$ of people without and with diabetes require biopsy. ${ }^{12} 32$

${ }^{*}$ Assumes that $75 \%{ }^{69}$ of people are treated with ACE inhibitor (generic ramipril $\$ 0.63 /$ day), and $25 \%$ with angiotensin blockers (irbesartan $\$ 1.21 /$ day) plus appropriate pharmacist prescribing fees.

††On average, people also receive calcium channel blocker and diuretic (Barrett et al, personal communication) at combined cost of $\$ 2.04 /$ day, plus appropriate pharmacist prescribing fees.

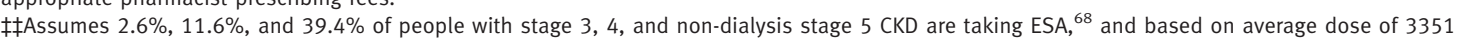
units/week ${ }^{68}$ (\$15.31/1000 units).

$\S \S$ Assumes that $2.7 \%$ of all people with GFR $<60 \mathrm{ml} / \mathrm{min} / 1.73 \mathrm{~m}^{2}$ are managed in multidisciplinary CKD clinic. $^{69}$

people without diabetes but with known hypertension, reflecting an increased prevalence of chronic kidney disease in people with hypertension, ${ }^{10}$ as well as a doubling of the risk of progression to end stage renal disease among people with hypertension. ${ }^{48}$ As the cost of managing people with chronic kidney disease varies based on practice patterns, we also assessed the impact of using alternative cost estimates on results.

To address limitations in classic univariate sensitivity analysis, we performed Monte Carlo simulation, which allows for the simultaneous sensitivity analysis of all variables over their plausible range. ${ }^{490}$ It does so by replacing estimates of probabilities, utilities, and costs with specific probability distributions, which are based on the reported means and variances for each variable. Statistical distributions were created around all of the variables for which there was substantial uncertainty of measurement, including use of a $\beta$ distribution for proportions (that is, the risk of end stage renal disease and mortality), use of a normal distribution for normally distributed variables (that is, certain costs, relative risks, and utility measures), and log normal distribution for skewed variables (that is, certain costs).

\section{RESULTS}

\section{Baseline analyses}

Compared with no screening, population based screening for chronic kidney disease was associated with an incremental cost of \$C463 and a gain of 0.0044 QALYs per patient overall, representing a cost per QALY gained of \$C104900 (table 6). In a cohort of 100000 people, screening would be expected to reduce the number of people developing end stage renal disease over their lifetime from 675 to 657 (fig 1). In subgroups of people aged $<65$ and $\geq 65$, the cost per QALY gained associated with screening was \$C 200100 and \$C93 700, respectively (table 6). 
Table 6 | Cost effectiveness of population based screening for chronic kidney disease and for targeted screening of high risk groups based on age, diabetes, and hypertension

\begin{tabular}{lccc} 
Outcome & $\begin{array}{c}\text { Incremental } \\
\text { cost }(\mathbf{S C})\end{array}$ & $\begin{array}{c}\text { Incremental } \\
\text { QALYs }\end{array}$ & $\begin{array}{c}\text { Cost }(\mathbf{S C}) \\
\text { per QALY }\end{array}$ \\
Overall & 463 & 0.0044 & 104900 \\
\hline Age $<65$ & 148 & 0.0007 & 200100 \\
\hline Age $\geq 65$ & 997 & 0.0106 & 93700 \\
\hline With diabetes & 578 & 0.0256 & 22600 \\
\hline Without diabetes & 440 & 0.0008 & 572000 \\
\hline $\begin{array}{l}\text { Without diabetes } \\
\text { and hypertension }\end{array}$ & 350 & 0.0003 & 1411100 \\
\hline $\begin{array}{l}\text { Without diabetes } \\
\text { with hypertension }\end{array}$ & 470 & 0.0014 & 334000 \\
\hline
\end{tabular}

In subgroups of people with and without diabetes, the cost per QALY gained was $\$ 22600$ and $\$ 572000$ , respectively. In a cohort of 100000 people with diabetes, screening would be expected to reduce the number of people developing end stage renal disease over their lifetime from 1796 to 1741 (fig 1). In people without diabetes with and without hypertension, the cost per QALY gained was \$C334 000 and \$C1 411100 , respectively (table 6 ).

\section{Sensitivity analyses}

Tables 7, 8, and 9 show the results of sensitivity analyses conducted for the model overall, while tables 10 and 11 show the results of sensitivity analyses on the effectiveness of angiotensin blockade in patients with and without diabetes, respectively. Sensitivity analyses showed that screening restricted to people with diabetes was generally associated with a cost per QALY gained of $<\$ 25000$, which was robust to changes in all plausible variables (tables 7-10). Screening in people without diabetes, however, was associated with a cost per QALY of around $\$ 50000$ only under scenarios

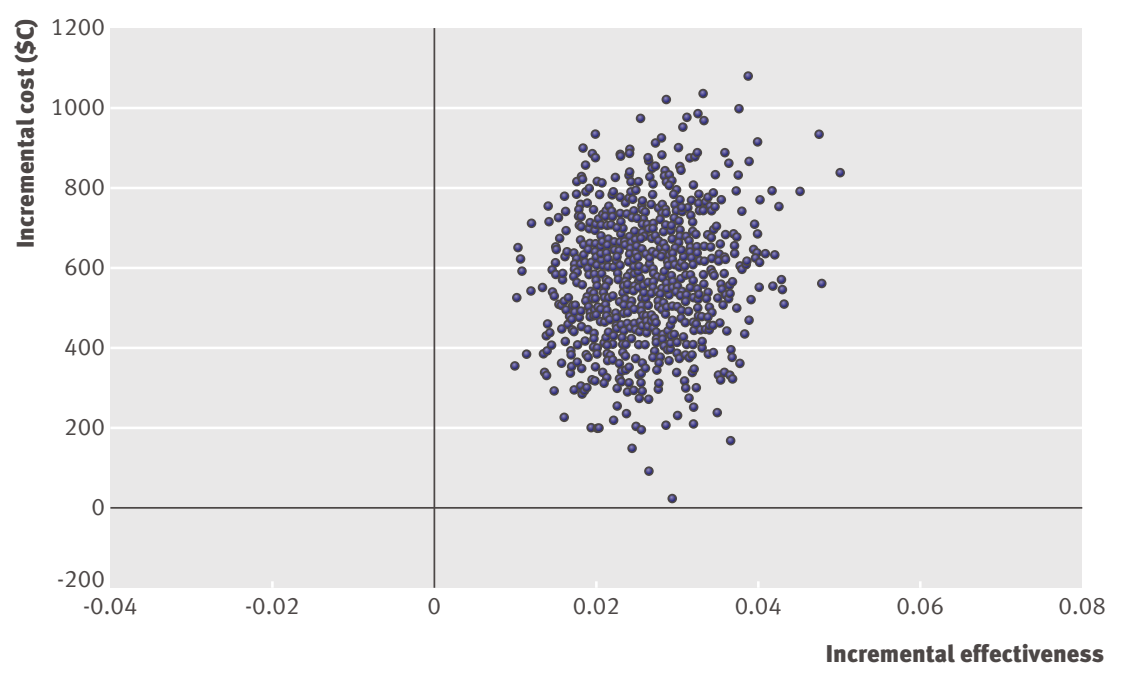

Fig 3 Incremental cost effectiveness scatterplot of population based screening for chronic kidney disease compared with no screening in people with diabetes where identification of chronic kidney disease would result in use of treatments that could improve survival by at least $15 \%$, and when the risk of progression to end stage renal disease in the absence of treatment was substantially higher than in the base case (table 11).

\section{Probabilistic sensitivity analysis}

Figures 2 and 3 show scatterplots of the incremental cost effectiveness of population based screening compared with no screening overall, highlighting uncertainty in the analysis, which is largely attributed to uncertainty regarding the impact of angiotensin blockade on mortality in people without diabetes and with chronic kidney disease. Given the current evidence of benefit for angiotensin blockade on both mortality and end stage renal disease in people with diabetes and chronic kidney disease, screening of people with diabetes led to better clinical outcomes in all simulations. Our analysis indicates a 37\% probability that targeted screening for chronic kidney disease among people with diabetes is associated with a cost per QALY gained of $<\$ 20000$ and a $99 \%$ probability that the cost per QALY gained is $<\$ 50000$.

\section{DISCUSSION}

Population based screening for chronic kidney disease is unlikely to be cost effective in unselected people or in those without diabetes. Although the prevalence of chronic kidney disease might be high enough to make screening worthy of consideration, particularly among older people, ${ }^{10}$ most people who would be found to have chronic kidney disease under a population based screening strategy would not have diabetes and would be likely to have non-proteinuric chronic kidney disease, relatively slow loss of kidney function, and low potential to benefit from angiotensin blockade. ${ }^{39}$ Therefore, the overall benefit of detecting and treating asymptomatic chronic kidney disease among people without diabetes is low. On the other hand, in people with diabetes, rates of progression to end stage renal disease are much higher, and there is strong evidence that angiotensin blockade reduces such progression ${ }^{333642}$ and improves survival. ${ }^{51}$ Given this, our study found that screening for chronic kidney disease in people with diabetes is associated with a cost per QALY in a range that is generally considered acceptable. ${ }^{52-54}$

\section{Strengths and limitations}

We modelled progression of chronic kidney disease and mortality stratified by age, diabetes, and presence or absence of proteinuria using a large cohort of patients with chronic kidney disease followed over five years and estimated the benefit of screening from high quality meta-analyses of angiotensin blockade. Given that previous analyses examining the cost effectiveness of screening have used urine based screening methods, ${ }^{12}{ }^{13}$ and as this might miss a considerable proportion of people with chronic kidney disease, ${ }^{10}$ we used estimated glomerular filtration rate to screen for 
Table 7|Sensitivity analysis of cost per QALY of screening for chronic kidney disease with varied rates of screening, use of angiotensin blockade, and adherence

\begin{tabular}{|c|c|c|c|}
\hline Outcome & Incremental cost $(\$ C)$ & Incremental QALYs & Cost (\$C) per QALY \\
\hline \multicolumn{4}{|l|}{ Baseline } \\
\hline Overall & 463 & 0.0044 & 104900 \\
\hline People with diabetes & 578 & 0.0256 & 22600 \\
\hline People without diabetes & 440 & 0.0008 & 572000 \\
\hline \multicolumn{4}{|c|}{ Screening adherence rate increased to $100 \%$ (baseline $50 \%$ ) } \\
\hline Overall & 926 & 0.0088 & 104900 \\
\hline People with diabetes & 1153 & 0.0511 & 22600 \\
\hline People without diabetes & 880 & 0.0015 & 572000 \\
\hline \multicolumn{4}{|c|}{ Adherence with angiotensin blockade increased to $100 \%$ (baseline $75 \%$ ) } \\
\hline Overall & 458 & 0.0059 & 77800 \\
\hline People with diabetes & 599 & 0.0341 & 16400 \\
\hline People without diabetes & 434 & 0.0010 & 423100 \\
\hline \multicolumn{4}{|c|}{$20 \%$ of patients already receiving angiotensin blockade (baseline $0 \%$ ) } \\
\hline Overall & 487 & 0.0035 & 141100 \\
\hline People with diabetes & 621 & 0.020 & 31100 \\
\hline People without diabetes & 464 & 0.0006 & 761100 \\
\hline
\end{tabular}

the presence of chronic kidney disease. One limitation of our analysis is that we did not compare our results to a strategy of screening with urinalysis or a combined strategy of glomerular filtration rate and urinalysis, though all patients detected as having chronic kidney disease were assumed to undergo urinalysis. Proteinuria is a powerful predictor of an increased risk of end stage renal disease and death in people with chronic kidney disease. ${ }^{55}$ While screening with estimated glomerular filtration rate might identify more people than screening with urinalysis, most people identified are at lower risk of adverse outcomes and do not seem to gain additional benefit from angiotensin blockade. $^{39}$

Our analysis was limited by the validity and availability of randomised trials (and meta-analyses) reporting the effectiveness of managing patients with chronic kidney disease. In general though, our analyses were guided by estimates of effectiveness from high quality meta-analyses. Screening in people without diabetes was unattractive given that angiotensin blockade does not seem to reduce mortality in people with non-diabetic renal disease. ${ }^{3839}$ When we assumed that angiotensin blockade reduced mortality by $16 \%$ among people without diabetes (consistent with results of a large trial in which most participants did not have chronic kidney disease ${ }^{37}$ ), the cost per QALY for screening people without diabetes became more attractive (\$40 800), though it is unclear whether this is a reasonable assumption. It could also be argued that people who are identified as having chronic kidney disease would be more likely to receive statins, which have been proved to improve survival in people with mild to moderate chronic kidney disease. ${ }^{56-59}$ In our analysis, however, we assumed that people at risk of cardiovascular events would already be receiving statins or aspirin (even without screening for chronic kidney disease). We therefore modelled only the impact of adding angiotensin blockade. In scenarios where we modelled the impact of treating identified patients with statins as well (resulting in a reduction in mortality of $16 \% 0^{58}$ at an additional cost of $\$ 620$ a year), then the cost per QALY for screening in people without diabetes was $\$ 53700$.

We assumed that the incidence of end stage renal disease and death, which was determined in a cohort of people with known chronic kidney disease, would be similar to a cohort of previously unidentified patients with chronic kidney disease who were detected through screening. Although this assumption might overestimate, or underestimate, the true risks, our results were robust to plausible changes in these variables. We also assumed that people with chronic kidney disease identified by screening would not be receiving angiotensin blockade, which seems reasonable given that they had not previously had their glomerular filtration rate measured. Of note, the results did not vary significantly when up to $20 \%$ of patients screened were already receiving angiotensin blockade. Finally, our results are most relevant to the Canadian setting. Given that our prevalence estimates are based

Table 8| Sensitivity analysis of cost per QALY for screening for chronic kidney disease (CKD) with varied incidence of disease and rates of progression to end stage renal disease (ESRD) in untreated patients

$\begin{array}{cccc}\text { Outcome } & \begin{array}{c}\text { Incremental } \\ \text { cost }(\$ C)\end{array} & \begin{array}{c}\text { Incremental } \\ \text { QALYs }\end{array} & \text { Cost }(\$ C) \\ \text { per QALY }\end{array}$

Baseline

\begin{tabular}{llll}
\hline Overall & 463 & 0.0044 & 104900 \\
\hline
\end{tabular}

\begin{tabular}{llll}
\hline People with diabetes & 578 & 0.0256 & 22600 \\
\hline
\end{tabular}

\begin{tabular}{llll}
\hline People without diabetes & 440 & 0.0008 & 572000
\end{tabular} Incidence of CKD increased by 50\% (baseline see table 4)

\begin{tabular}{llll}
\hline Overall & 682 & 0.0066 & 103000 \\
\hline People with diabetes & 853 & 0.0384 & 22200
\end{tabular}

\begin{tabular}{llll}
\hline People without diabetes & 646 & 0.0012 & 547400
\end{tabular}
Incidence of CKD decreased by $50 \%$ (baseline see table 4)

\begin{tabular}{llll}
\hline Overall & 244 & 0.0022 & 110300 \\
\hline
\end{tabular}

\begin{tabular}{llll}
\hline People with diabetes & 300 & 0.0128 & 23500 \\
\hline
\end{tabular}

\begin{tabular}{llll}
\hline People without diabetes & 232 & 0.0004 & 603300
\end{tabular} Reduce risk of progression to ESRD by $50 \%$ (baseline see table 2)

\begin{tabular}{|c|c|c|c|}
\hline Overall & 521 & 0.0041 & 126400 \\
\hline People with diabetes & 682 & 0.0259 & 26300 \\
\hline People without diabetes & 495 & 0.0004 & 1172900 \\
\hline \multicolumn{4}{|c|}{ Reduce risk of progression to ESRD by $25 \%$ (baseline see table 2) } \\
\hline Overall & 490 & 0.0043 & 114500 \\
\hline People with diabetes & 623 & 0.0257 & 24183 \\
\hline People without diabetes & 465 & 0.0006 & 771100 \\
\hline \multicolumn{4}{|c|}{ Increase risk of progression to ESRD by $50 \%$ (baseline see table 2) } \\
\hline Overall & 420 & 0.0046 & 90400 \\
\hline People with diabetes & 513 & 0.0252 & 20351 \\
\hline People without diabet & 398 & 0.0011 & 376500 \\
\hline
\end{tabular}
Increase risk of progression to ESRD by $100 \%$ (baseline see table 2)

\begin{tabular}{llll}
\hline Overall & 387 & 0.0048 & 80200 \\
\hline People with diabetes & 474 & 0.0249 & 19100 \\
\hline People without diabetes & 367 & 0.0013 & 282200 \\
\hline
\end{tabular}


Table 9| Sensitivity analysis of cost per QALY for screening for chronic kidney disease (CKD), exploring impact of variations in costs and quality of life

\begin{tabular}{|c|c|c|c|}
\hline Outcome & Incremental cost (\$C) & Incremental QALYs & Cost (\$C) per QALY \\
\hline \multicolumn{4}{|l|}{ Baseline } \\
\hline Overall & 463 & 0.0044 & 104900 \\
\hline People with diabetes & 578 & 0.0256 & 22600 \\
\hline People without diabetes & 440 & 0.0008 & 572000 \\
\hline \multicolumn{4}{|c|}{ Costs for screening, CKD management, dialysis, and transplantation increased $50 \%$} \\
\hline Overall & 695 & 0.0044 & 157000 \\
\hline People with diabetes & 865 & 0.0256 & 33800 \\
\hline People without diabetes & 660 & 0.0008 & 857900 \\
\hline \multicolumn{4}{|c|}{ Costs for screening, CKD management, dialysis, and transplantation decreased $50 \%$} \\
\hline Overall & 232 & 0.0044 & 52400 \\
\hline People with diabetes & 295 & 0.0256 & 11500 \\
\hline People without diabetes & 220 & 0.0008 & 286000 \\
\hline
\end{tabular}

Assuming newly diagnosed patients will have no additional cost for antihypertensive medications

\begin{tabular}{lccc}
\hline Overall & 177 & 0.0044 & 40100 \\
\hline People with diabetes & 175 & 0.0256 & 6900 \\
\hline People without diabetes & 169 & 0.0008 & 219800 \\
\hline Physician costs for screening (both GP visits) reduced to 0 (baseline \$C35.26)* & \\
\hline Overall & 445 & 0.0044 & 100800 \\
\hline People with diabetes & 558 & 0.0256 & 21800 \\
\hline People without diabetes & 422 & 0.0008 & 548500 \\
\hline
\end{tabular}

Only $20 \%$ of people with stage 3 disease referred to specialist (remaining $80 \%$ managed by GP)

\begin{tabular}{lllc}
\hline Overall & 416 & 0.0044 & 94247 \\
\hline People with diabetes & 514 & 0.0256 & 20116 \\
\hline People without diabetes & 395 & 0.0008 & 513478
\end{tabular}

Annual cost of medication, physicians fees, and laboratory costs associated with managing patients with diagnosis increased by $50 \%$

\begin{tabular}{lccc}
\hline Overall & 745 & 0.0044 & 168700 \\
\hline People with diabetes & 975 & 0.0256 & 38100 \\
\hline People without diabetes & 706 & 0.0008 & 918300 \\
\hline Annual cost of dialysis increased by $50 \%$ (baseline \$C64 218) & & \\
\hline Overall & 420 & 0.0044 & 100 \\
\hline People with diabetes & 501 & 0.0256 & 519000 \\
\hline People without diabetes & 399 & 0.0008 & \\
\hline Annual cost of dialysis decreased by $50 \%$ (baseline \$C64 218) & & 100500 \\
\hline Overall & 444 & 0.0044 & 20800 \\
\hline People with diabetes & 531 & 0.0256 & 548600 \\
\hline People without diabetes & 422 & 0.0008 & \\
\hline
\end{tabular}

High estimate utility value (0.90) associated with living with CKD (baseline 0.85 )

\begin{tabular}{lccc}
\hline Overall & 463 & 0.0048 & 97100 \\
\hline Diabetes & 577 & 0.0273 & 21200 \\
\hline Non-diabetes & 440 & 0.0009 & 488700
\end{tabular}

Low estimate utility value (0.75) associated with living with CKD (baseline 0.85)

\begin{tabular}{lccc}
\hline Overall & 463 & 0.0037 & 124700 \\
\hline Diabetes & 577 & 0.0222 & 26000 \\
\hline Non-diabetes & 440 & 0.00051 & 867400
\end{tabular}

Discount rates decreased to $0 \%{ }^{71}$ (baseline $5 \%$ )

\begin{tabular}{lccc}
\hline Overall & 622 & 0.0087 & 71800 \\
\hline People with diabetes & 796 & 0.0536 & 14800 \\
\hline People without diabetes & 588 & 0.0011 & 520200 \\
\hline Discount rates decreased to $3 \%^{71}$ (baseline $\left.5 \%\right)$ & & 91084 \\
\hline Overall & 515 & 0.0057 & 19250 \\
\hline People with diabetes & 645 & 0.0335 & 540733 \\
\hline People without diabetes & 489 & 0.0009 &
\end{tabular}

ESRD=end stage renal disease.

*Assumes that CKD screening would be done during annual visit and costs of screening would include only cost of laboratory tests. on a large North American cohort study, ${ }^{10}$ our estimates of efficacy based on randomised trials conducted throughout the world, and that Canada has publicly funded healthcare and relative costs that are likely similar to Europe, we think that our results are likely to be valid in other countries.

\section{Comparison with other studies}

Previous studies have examined only the cost effectiveness of screening with urinalysis or urine based quantitative proteinuria. ${ }^{12} 1360$ Like our study, these studies found that targeted screening of high risk groups (but not population based screening) might be cost effective. ${ }^{12} 13$ An analysis by Boulware et al suggested that screening for chronic kidney disease with measurement of proteinuria in patients with hypertension was associated with a cost per QALY of less than US \$ $20000{ }^{12}$ These analyses, however, assumed that angiotensin blockade would improve survival in people without diabetes, ${ }^{12}$ an assumption not supported by available data in patients with chronic kidney disease. ${ }^{3839}$ A study examining the cost effectiveness of population based screening for urinary albumin excretion, with treatment of those noted to have albumin excretion $>15 \mathrm{mg} /$ day with fosinopril to prevent cardiovascular events, based on the PREVEND study cohort, reported a cost per life year gained of $€ 16700 .^{60}$

Population based screening for chronic kidney disease has been advocated by some, ${ }^{41516}$ and the National Kidney Foundation/Kidney Dialysis Outcomes Quality Initiative clinical practice guidelines for chronic kidney disease have recommended screening for people at high risk of kidney disease, including those with diabetes and hypertension and aged over $60 .{ }^{14}$ Given that considerable resources would be required to set up a population based screening programme, our results are important. Our analyses suggest that screening for chronic kidney disease with estimated glomerular filtration rate is not cost effective in older people or in those without diabetes with hypertension but for people with diabetes is associated with a cost per QALY gained in the range of other funded interventions. We could not determine whether screening with urinalysis might be more cost effective overall or in certain subgroups compared with estimated glomerular filtration rate.

\section{Conclusions}

Our results suggest that population based screening for chronic kidney disease with assessment of estimated glomerular filtration rate is not cost effective overall or in subgroups of people without diabetes but with hypertension or in elderly people. Targeted chronic kidney disease screening with estimated glomerular filtration rate in people with diabetes is associated with a cost per QALY that is similar to other publicly funded interventions. 
Table 10 | Sensitivity analysis of effectiveness of angiotensin blockade for management of CKD in people with diabetes

\begin{tabular}{|c|c|c|c|}
\hline Outcome & $\begin{array}{l}\text { Incremental cost } \\
\qquad(\$ C)\end{array}$ & $\begin{array}{l}\text { Incremental } \\
\text { QALYs }\end{array}$ & $\begin{array}{l}\text { Cost (\$C) } \\
\text { per QALY }\end{array}$ \\
\hline Baseline & 578 & 0.0256 & 22600 \\
\hline \multicolumn{4}{|l|}{ Scenario analyses on relative risk (RR) of mortality associated with angiotensin blockade } \\
\hline $\begin{array}{l}\text { RR mortality with and without proteinuria improved to } 0.75 \text { (baseline } 0.79 \text { for patients } \\
\text { with proteinuria and } 0.84 \text { without proteinuria) }\end{array}$ & 633 & 0.0378 & 16700 \\
\hline $\begin{array}{l}\text { Best case scenario: RR mortality with angiotensin blockade improved to } 0.75 \text { (as above) } \\
\text { and } 1.5 \text {-fold increased risk of progression to ESRD for untreated patients }\end{array}$ & 579 & 0.0371 & 15600 \\
\hline $\begin{array}{l}\text { Worst case scenario: RR mortality with and without proteinuria increased to } 0.95 \\
\text { (baseline as above) }\end{array}$ & 464 & 0.0079 & 58700 \\
\hline \multicolumn{4}{|l|}{ Scenario analyses on relative risk of ESRD associated with angiotensin blockade } \\
\hline $\begin{array}{l}\text { RR of developing ESRD in patients with CKD and diabetes with and without proteinuria } \\
\text { from angiotensin blockade improved to } 0.5 \text { and } 0.72 \text {, respectively (baseline } 0.64 \text { for } \\
\text { patients with proteinuria and } 1.0 \text { without proteinuria) }\end{array}$ & 301 & 0.0274 & 11000 \\
\hline $\begin{array}{l}\text { RR of developing ESRD in patients with CKD and diabetes with and without proteinuria } \\
\text { from angiotensin blockade increase to } 0.9 \text { and } 1.0 \text {, respectively (baseline as above) }\end{array}$ & 839 & 0.0204 & 35000 \\
\hline
\end{tabular}

Table 11|Sensitivity analysis of effectiveness of angiotensin blockade for management of CKD in people without diabetes

\begin{tabular}{|c|c|c|c|}
\hline Outcome & $\begin{array}{l}\text { Incremental cost } \\
\qquad(\$ C)\end{array}$ & $\begin{array}{l}\text { Incremental } \\
\text { QALYs }\end{array}$ & $\begin{array}{l}\text { Cost (\$C) } \\
\text { per QALY }\end{array}$ \\
\hline Baseline & 440 & 0.0008 & 572000 \\
\hline \multicolumn{4}{|l|}{ Scenario analyses on relative risk (RR) of mortality associated with angiotensin blockade } \\
\hline RR mortality in people with and without proteinuria improved to $0.84^{37}$ (baseline 1.0 ) & 480 & 0.0118 & 40800 \\
\hline $\begin{array}{l}\text { RR mortality in people with and without proteinuria increased to } 2.17 \text { (table 4) (baseline } \\
\text { 1.0) }\end{array}$ & 250 & -0.052 & Dominated \\
\hline $\begin{array}{l}\text { Addition of statin to all patients found to have CKD: assumes all people without diabetes } \\
\text { found to have CKD also receive statin and that this improves survival by } 16 \%,{ }^{58} \\
\text { incorporated additional costs of statin }\end{array}$ & 633 & 0.0118 & 53700 \\
\hline \multicolumn{4}{|l|}{ Scenario analyses on relative risk of ESRD associated with angiotensin blockade } \\
\hline $\begin{array}{l}\text { RR of developing ESRD associated with angiotensin blockade improves to } 0.52 \text { and } 1.0 \\
\text { for patients with and without proteinuria, respectively (baseline } 0.59 \text { for patients with } \\
\text { proteinuria and } 1.01 \text { without proteinuria) }\end{array}$ & 417 & 0.0009 & 448900 \\
\hline $\begin{array}{l}\text { RR of developing ESRD associated with angiotensin blockade is less attractive at } 0.9 \text { and } \\
1.2 \text { for patients with and without proteinuria, respectively (baseline as above) }\end{array}$ & 549 & -0.0002 & Dominated \\
\hline
\end{tabular}

$\mathrm{CKD}=$ chronic kidney disease; $\mathrm{ESRD}=$ end stage renal disease.

Contributors: BM, SK, MT, and BH made substantial contributions to study conception and design, drafting, and critical revision. BM, SK, BH, FA, JD, and TCC were involved with data analysis and interpretation of data. BM is guarantor.

Funding: This study was supported by an operating grant from Alberta Heritage Foundation for Medical Research (now Alberta Innovates-Health Solutions). The infrastructure required for this research was also supported by the Alberta Heritage Foundation for Medical Research Interdisciplinary Team Grants Program (which supports the Interdisciplinary Chronic Disease Collaboration). The funding organisations played no role in the design and conduct of the study;

\section{WHAT IS ALREADY KNOWN ON THIS TOPIC}

Chronic kidney disease is common, and in many patients is asymptomatic and remains undiagnosed

Previous analyses have examined the cost effectiveness of screening with urinalysis rather than estimated glomerular filtration rate, the standard method for diagnosing chronic kidney disease

\section{WHAT THIS STUDY ADDS}

Population based screening for chronic kidney disease with estimated glomerular filtration rate assessment is not cost effective overall

Targeted screening of people with diabetes is associated with an acceptable cost per QALY in publicly funded healthcare systems. collection, management, analysis, and interpretation of the data; and preparation, review, or approval of the manuscript. BM, MT, and BH are supported by New Investigator Awards from the Canadian Institutes of Health Research and MT, SK, BM, and BH are supported by salary awards from Alberta Innovates-Health Solutions.

Competing interests: All authors have completed the Unified Competing Interest form at www.icmje.org/coi_disclosure.pdf (available on reques from the corresponding author) and declare: this project was supported by an operating grant from Alberta Heritage Foundation for Medical Research (now Alberta Innovates-Health Solutions) for the submitted work; no financial relationships with any companies that might have an interest in the submitted work in the previous 3 years; no other relationships or activities that could appear to have influenced the submitted work.

Ethical approval: This study was approved by the Calgary Health Region ethics board.

Data sharing: No additional data available.

1 National Kidney Foundation. K/DOQI clinical practice guidelines for chronic kidney disease: evaluation, classification, and stratification. Am J Kidney Dis 2002;39(suppl 1):1-266s.

2 Powe NR, Boulware LE. Population-based screening for CKD. Am Kidney Dis 2009;53(suppl 3):64-70s.

3 Powe NR, Plantinga L, Saran R. Public health surveillance of CKD: principles, steps, and challenges. Am J Kidney Dis 2009;53(suppl 3):37-45s.

4 McClellan WM, Ramirez SP, Jurkovitz C. Screening for chronic kidney disease: unresolved issues. J Am Soc Nephrol 2003;14(suppl 2):81-7s. 
5 Brown WW, Collins A, Chen SC, King K, Molony D, Gannon MR, et al. Identification of persons at high risk for kidney disease via targeted screening: the NKF Kidney Early Evaluation Program. Kidney Int Suppl 2003;83:50-5s.

6 McGill JB, Brown WW, Chen SC, Collins AJ, Gannon MR. Kidney Early Evaluation Program (KEEP). Findings from a community screening program. Diabetes Educ 2004;30:196-8,200-2,206.

7 Ohmit SE, Flack JM, Peters RM, Brown WW, Grimm R. Longitudinal study of the National Kidney Foundation's (NKF) Kidney Early Evaluation Program (KEEP). J Am Soc Nephrol 2003;14(suppl 2):117-21s.

8 Vassalotti JA, Li S, Chen SC, Collins AJ. Screening populations at increased risk of CKD: the Kidney Early Evaluation Program (KEEP) and the public health problem. Am J Kidney Dis 2009;53(suppl 3):107-14s.

9 Whaley-Connell A, Sowers JR, McCullough PA, Roberts T, McFarlane SI, Chen SC, et al. Diabetes mellitus and CKD awareness: the Kidney Early Evaluation Program (KEEP) and National Health and Nutrition Examination Survey (NHANES). Am J Kidney Dis 2009;53(suppl 4):11-21s.

10 Garg AX, Kiberd BA, Clark WF, Haynes RB, Clase CM. Albuminuria and renal insufficiency prevalence guides population screening: results from the NHANES III. Kidney Int 2002;61:2165-75.

11 Hallan SI, Dahl K, Oien CM, Grootendorst DC, Aasberg A, Holmen J, et al. Screening strategies for chronic kidney disease in the general population: follow-up of cross sectional health survey. BMJ 2006;333:1047.

12 Boulware LE, Jaar BG, Tarver-Carr ME, Brancati FL, Powe NR. Screening for proteinuria in US adults: a cost-effectiveness analysis. IAMA 2003;290:3101-14.

13 Craig JC, Barratt A, Cumming R, Irwig L, Salkeld G. Feasibility study of the early detection and treatment of renal disease by mass screening. Intern Med / 2002;32:6-14.

14 Chobanian AV, Bakris GL, Black HR, Cushman WC, Green LA, Izzo JL Jr, et al. Seventh report of the joint national committee on prevention, detection, evaluation, and treatment of high blood pressure. Hypertension 2003;42:1206-52.

15 Ramirez SP. Chronic kidney disease prevention in Singapore. Clin J Am Soc Nephrol 2008;3:610-5.

16 Ramirez SP, Hsu SI, McClellan W. Taking a public health approach to the prevention of end-stage renal disease: the NKF Singapore Program. Kidney Int Suppl 2003;83:61-5s.

17 Smith JM, Mott SA, Hoy WE. Status of chronic kidney disease prevention programs: International Federation of Kidney Foundation Members 2005/2007. Kidney Int 2008;74:1516-25.

18 Hemmelgarn BR, Clement F, Manns BJ, Klarenbach S, James MT, Ravani $\mathrm{P}$, et al. Overview of the Alberta Kidney Disease Network. BMC Nephrol 2009;10:30.

19 Canadian Agency for Drugs and Technologies in Health. Guidelines for the economic evaluation of health technologies. 3rd ed. Canadian Agency for Drugs and Technologies in Health, 2006.

20 Weinstein MC, O'Brien B, Hornberger J, Jackson J, Johannesson M, $\mathrm{McC}$ abe $\mathrm{C}$, et al. Principles of good practice for decision analytic modeling in health-care evaluation: report of the ISPOR Task Force on Good Research Practices-modeling studies. Value Health 2003;6:9-17.

21 Johnson ES, Thorp ML, Platt RW, Smith DH. Predicting the risk of dialysis and transplant among patients with CKD: a retrospective cohort study. Am J Kidney Dis 2008;52:653-60.

22 Peralta CA, Shlipak MG, Fan D, Ordonez J, Lash JP, Chertow GM, et al. Risks for end-stage renal disease, cardiovascular events, and death in Hispanic versus non-Hispanic white adults with chronic kidney disease. J Am Soc Nephrol 2006;17:2892-9.

23 National Center for Health Statistics. Plan and operation of the Third National Health and Nutrition Examination Survey, 1988-94. Vital Health Stat 1994:1:1-407.

24 Manns BJ, Mortis G, Taub K, McLaughlin K, Donaldson C, Ghali WA. The Southern Alberta Renal Program Database: a prototype for patient management and research initiatives. Clin Invest Med 2001;24:164-70.

25 Levey AS, Bosch JP, Lewis JB, Greene T, Rogers N, Roth D. Modification of Diet in Renal Disease Study Group. A more accurate method to estimate glomerular filtration rate from serum creatinine: a new prediction equation. Ann Intern Med 1999;130:461-70.

26 Hux JE, Ivis F, Flintoft V, Bica A. Diabetes in Ontario: determination of prevalence and incidence using a validated administrative data algorithm. Diabetes Care 2002;25:512-6.

27 Quan H, Parsons GA, Ghali WA. Validity of information on comorbidity derived ROM ICD-9-CCM administrative data. Med Care 2002;40:675-85.

28 Quan H, Sundararajan V, Halfon P, Fong A, Burnand B, Luthi JC, et al. Coding algorithms for defining comorbidities in ICD-9-CM and ICD-10 administrative data. Med Care 2005;43:1130-9.

29 Statistics Canada. Consumer price index for Canada (health care [not seasonally adjusted] 1972-2007). Statistics Canada, 2008
30 National Committee for Quality Assurance. State of health care quality report. NCQA, 2003. www.ncqa.org/Portals/0/Publications/ Resource\%20Library/SOHC/SOHC 2003.pdf.

31 Statistics Canada. 2006 Canada census. Statistics Canada, 2007

32 Fuiano G, Mazza G, Comi N, Caglioti A, De Nicola L, lodice C, et al. Current indications for renal biopsy: a questionnaire-based survey. Am J Kidney Dis 2000;35:448-57.

33 Brenner BM, Cooper ME, de Zeeuw D, Keane WF, Mitch WE, Parving $\mathrm{HH}$, et al. Effects of losartan on renal and cardiovascular outcomes in patients with type 2 diabetes and nephropathy. N EnglJ Med 2001;345:861-9.

34 De Zeeuw D, Lewis EJ, Remuzzi G, Brenner BM, Cooper ME. Renoprotective effects of renin-angiotensin-system inhibitors. Lancet 2006;367:899-900

35 Strippoli GF, Craig M, Deeks JJ, Schena FP, Craig JC. Effects of angiotensin converting enzyme inhibitors and angiotensin II receptor antagonists on mortality and renal outcomes in diabetic nephropathy: systematic review. BMJ 2004;329:828.

36 Lewis EJ, Hunsicker LG, Bain RP, Rohde RD. The effect of angiotensinconverting-enzyme inhibition on diabetic nephropathy. N Engl J Med 1993;329:1456-62

37 Yusuf S, Sleight P, Pogue J, Bosch J, Davies R, Dagenais G. The Heart Outcomes Prevention Evaluation Study Investigators. Effects of an angiotensin-converting-enzyme inhibitor, ramipril, on cardiovascular events in high-risk patients. N Engl J Med 2000;342:145-53.

38 Giatras I, Lau J, Levey AS. Angiotensin-Converting-Enzyme Inhibition and Progressive Renal Disease Study Group. Effect of angiotensinconverting enzyme inhibitors on the progression of nondiabetic renal disease: a meta-analysis of randomized trials. Ann Intern Med 1997; 127:337-45

39 Jafar TH, Schmid CH, Landa M, Giatras I, Toto R, Remuzzi G, et al. Angiotensin-converting enzyme inhibitors and progression of nondiabetic renal disease. A meta-analysis of patient-level data. Ann Intern Med 2001;135:73-87.

40 Agodoa LY, Appel L, Bakris GL, Beck G, Bourgoignie J, Briggs JP, et al. Effect of ramipril vs amlodipine on renal outcomes in hypertensive nephrosclerosis: a randomized controlled trial. JAMA 2001;285:2719-28

41 Wright JT Jr, Bakris G, Greene T, Agodoa LY, Appel LJ, Charleston J, et al. Effect of blood pressure lowering and antihypertensive drug class on progression of hypertensive kidney disease: results from the AASK trial. JAMA 2002;288:2421-31.

42 Lewis El, Hunsicker LG, Clarke WR, Berl T, Pohl MA, Lewis JB, et al. Renoprotective effect of the angiotensin-receptor antagonist irbesartan in patients with nephropathy due to type 2 diabetes. $N$ Engl/ Med 2001;345:851-60.

43 Canadian Organ Replacement Registry. Treatment of end-stage organ failure in Canada 2002 and 2003. Canadian Institutes of Health Information, 2005.

44 Lee H, Manns B, Taub K, Ghali WA, Dean S, Johnson D, et al. Cost analysis of ongoing care of patients with end-stage renal disease: the impact of dialysis modality and dialysis access. Am J Kidney Dis 2002;40:611-22.

45 Laupacis A, Keown P, Pus N, Krueger H, Ferguson B, Wong C, et al. A study of the quality of life and cost-utility of renal transplantation. Kidney Int 1996;50:235-42.

46 Okano Y, Tamura K, Masuda S, Ozawa M, Tochikubo O, Umemura S. Effects of angiotensin II receptor blockers on the relationships between ambulatory blood pressure and anti-hypertensive effects, autonomic function, and health-related quality of life. Clin Exp Hypertens 2009;31:680-9.

47 Manns B, Johnson JA, Taub K, Mortis G, Ghali WA, Donaldson C. Quality of life in patients treated with hemodialysis or peritoneal dialysis: what are the important determinants? Clin Nephrol 2003;60:341-51.

48 Ruggenenti P, Perna A, Gherardi G, Benini R, Remuzzi G. Chronic proteinuric nephropathies: outcomes and response to treatment in a prospective cohort of 352 patients with different patterns of renal injury. Am J Kidney Dis 2000;35:1155-65.

49 Briggs A. Uncertainty in the economic evaluation of health care technologies: the role of sensitivity analysis. Health Econ 1994;3:95-104.

50 Briggs A, Fenn P. Confidence intervals or surfaces? Uncertainty on the cost-effectiveness plane. Health Econ 1998;7:723-40.

51 Lindholm LH, Ibsen H, Dahlof B, Devereux RB, Beevers G, de Faire U, et al. Cardiovascular morbidity and mortality in patients with diabetes in the Losartan Intervention For Endpoint reduction in hypertension study (LIFE): a randomised trial against atenolol. Lancet 2002;359:1004-10.

52 Gold R, Siegel J, Russell L, Weinstein M. Cost-effectiveness in health and medicine. Oxford University Press, 1996.

53 Laupacis A, Feeny D, Detsky AS, Tugwell PX. How attractive does a new technology have to be to warrant adoption and utilization? Tentative guidelines for using clinical and economic evaluations. CMAI 1992;146:473-81. 
54 Clement FC, Harris A, Li JJ, Yong K, Lee KM, Manns BJ. Using effectiveness and cost effectiveness to make drug coverag decisions: a comparison of Britain, Australia and Canada. JAMA 2009;302:1437-43.

55 Hemmelgarn B, Manns B, Lloyd A, James MT, Klarenbach S, Quinn R, et al. Relation between kidney function, proteinuria, and adverse outcomes. JAMA 2010;303:423-9.

56 Tonelli M, Bohm C, Pandeya S, Gill J, Levin A, Kiberd BA. Cardiac risk factors and the use of cardioprotective medications in patients with chronic renal insufficiency. Am J Kidney Dis 2001;37:484-9.

57 Tonelli M, Isles C, Craven T, Tonkin A, Pfeffer MA, Shepherd J, et al. Effect of pravastatin on rate of kidney function loss in people with or at risk for coronary disease. Circulation 2005;112:171-8.

58 Tonelli M, Isles C, Curhan GC, Tonkin A, Pfeffer MA, Shepherd J, et al. Effect of pravastatin on cardiovascular events in people with chronic kidney disease. Circulation 2004;110:1557-63.

59 Tonelli M, Keech A, Shepherd J, Sacks F, Tonkin A, Packard C, et al. Effect of pravastatin in people with diabetes and chronic kidney disease. J Am Soc Nephrol 2005;16:3748-54.

60 Atthobari J, Asselbergs FW, Boersma C, de Vries R, Hillege HL, van Gilst WH, et al. Cost-effectiveness of screening for albuminuria with subsequent fosinopril treatment to prevent cardiovascular events: a pharmacoeconomic analysis linked to the prevention of renal and vascular endstage disease (PREVEND) study and the prevention of renal and vascular endstage disease intervention trial (PREVEND IT) Clin Ther 2006;28:432-44.

61 Johnson JA. Alberta diabetes atlas 2009. Institute of Health Economics, 2009.

62 Wolfe RA, Ashby VB, Milford EL, Ojo AO, Ettenger RE, Agodoa LY, et al. Comparison of mortality in all patients on dialysis, patients on dialysis awaiting transplantation, and recipients of a first cadaveric transplant. N Engl J Med 1999;341:1725-30.

63 Gorodetskaya I, Zenios S, McCulloch CE, Bostrom A, Hsu CY, Bindman $A B$, et al. Health-related quality of life and estimates of utility in chronic kidney disease. Kidney Int 2005;68:2801-8.
64 Manns BJ, Jeffrey J, Ken T, Garth M, William G, Donaldson C. Quality of life in patients with end-stage renal disease over time: the impact of dialysis modality and other important determinants. Institute of Health Economics working paper. Institute of Health Economics, 2005.

65 Heart Outcomes Prevention Evaluation Study Investigators. Effects of ramipril on cardiovascular and microvascular outcomes in people with diabetes mellitus: results of the HOPE study and MICRO-HOPE substudy. Lancet 2000;355:253-9.

66 Maschio G, Alberti D, Janin G, Locatelli F, Mann JF, Motolese M, et al. The Angiotensin-Converting-Enzyme Inhibition in Progressive Renal Insufficiency Study Group. Effect of the angiotensin-convertingenzyme inhibitor benazepril on the progression of chronic renal insufficiency. N Engl J Med 1996;334:939-45.

67 Alberta Government. Alberta health and wellness drug benefit list. Alberta Government, 2010

68 Tonelli MKS, Wiebe N, Shrive F, Hemmelgarn B, Manns B. Erythropoiesis-stimulating agents for anemia of chronic kidney disease: systematic review and economic evaluation. Canadian Agency for Drugs and Technologies in Health, 2008 (Technology Report No 106).

69 Hemmelgarn BR, Manns BJ, Zhang J, Tonelli M, Klarenbach S, Walsh M, et al. Association between multidisciplinary care and survival for elderly patients with chronic kidney disease. J Am Soc Nephrol 2007;18:993-9.

70 McLaughlin K, Manns B, Culleton B, Donaldson C, Taub K. An economic evaluation of early versus late referral of patients with progressive renal insufficiency. Am J Kidney Dis 2001;38:1122-8.

71 Canadian Agency for Drugs and Technologies in Health. Guidelines for the economic evaluation of health technologies. 3rd ed. CADTH, 2006.

Accepted: 2 September 2010 